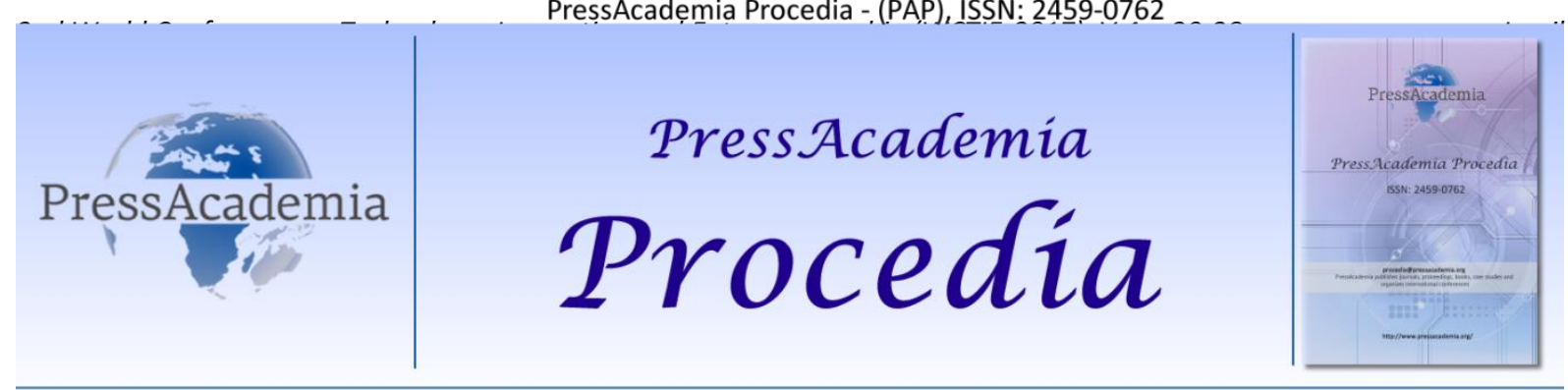

2nd World Conference on Technology, Innovation and Entrepreneurship

May 12-14, 2017, Istanbul, Turkey. Edited by Sefer Şener

\title{
DEPLOYING KNOWLEDGE MANAGEMENT IN DMAIC METHODOLOGY OF SIX SIGMA PROJECTS
}

\author{
DOI: 10.17261/Pressacademia.2017.511 \\ PAP-WCTIE-V.4-2017(3)-p.20-28
}

Muhammad Yousaf Jamil

University of Management \& Technology, Lahore, Pakistan. yousaf.jamil@umt.edu.pk, yousafjamil@gmail.com

\begin{abstract}
Six Sigma, as a tremendous acclimated method for doing things, moves towards steady and plausible change by developing buyer dependability and reducing action time and number of imperfections. On the other hand, Knowledge Management (KM) is a most recent approach that strategies with the uncommon asset of affiliation i.e. data. In this exploration, resulting to evaluating the looks into of examination on this alliance, the linkage amongst KM and 6-sigma is investigated and in conclusion usage of KM instruments in parts of DMAIC procedure as a sensible and valuable system for6-sigma, have been secured. Both KM and 6-sigma are quickly cautious business association frameworks with essential thinking and process improvement strategies, Specialists in both fields can get benefit from each other. 6-sigma can get from KM how to be acquainted with Knowledge furthermore forms. 6-sigma specialists also can pick up from KM systems that care for change. 6-sigma is an apparent methodology for Quality and strategy updating with observable quality on deformity obstruction instead of yield detection. By decreasing assortment and waste at the same time, fundamental concern comes about and persistent change are to be progressed. KM of course is proposed at rolling out handy improvement, too. At the end of this study, the author proposes the conceptual framework about the perceived benefits which Knowledge based and 6-sigma oriented organization can achieve after implementation of these best practices.
\end{abstract}

Keywords: Knowledge Management (KM), 6-sigma, Tacit Knowledge (TK), Explicit Knowledge (EK), DMAIC methodology, etc. JEL Codes: K12

\section{INTRODUCTION}

As organizations have begun giving careful consideration towards enhancing their operational business practices, KM and Six Sigma technique has reformed the universe of business and advanced with developing energy in consumer loyalty and quality. In the changing business environment, the key component required for supporting or building aggressive favorable position is the capacity of an organization to react proactively through operational and task Knowledge and related advancements. Competition has turned out to be increasingly savage, clients are demanding higher quality at lower costs and net revenues appear to fall particularly in times of emergency. A proficient and compelling procedure to end up more focused is to embrace KM and Six Sigma. The imperativeness of knowledge innovative strength and knowledge value in enhancing activities of organizational Quality was driving forward and harmonized by the experts in Quality Assurance arena. In resentment of the way that making of accompanying organizational knowledge for change execution, various leveled operations, effectiveness augment and increasing extra advantage were the all points considered of these two frameworks, and 6-sigma endeavors are in like way based after fitting data and its stream, a practical relationship can be seen between them. Along these lines, there is a strong relationship between $\mathrm{KM}$ and 6 -sigma. Both of two anticipated at positive additional categorized information for performance improvement Duguid, (2000). Treichler et al. (2002) reasoned that Six Sigma is a much trained procedure that helps associations to concentrate on creating and conveying close impeccable items and organizations. It is likewise, in Treichlers' (2002) view, a change-speeding up procedure that spotlights on seeking after achievement and the fast appropriation of progress. The significance of Knowledge creativity and learning part in improvement exercises of organization quality was managed and affirmed by the specialists in quality science fields. The best endeavors and extraordinary attempt if are not in view of learning prompts awesome profundity of the current gap. Both of them aimed at certain more organizational knowledge for performance improvement. In this way, there is a cozy relationship between Knowledge Management (KM) and Six Sigma. In the event that KM and Six Sigma are consolidated together, a capable administration technique will be accomplished. KM framework gives an immediate access 
to taking care of the issues in Six Sigma ventures. Sung H. Park (2003). Each of them additionally intends to bolster development and productivity and force another. Kevin D. Barber and J. E. Munive-Hernandez, (2006). Together KM and Six Sigma are a perfect fit for improving the quality of product / service delivery and support. S. Choo (2007). The Six Sigma approach is well positioned to provide quantifiable measures of process performance outcomes and a consistent approach through the DMAIC (Define, Measure, Analyze, Improve and Control) quality improvement cycle, in how and when to use the metrics. In the event that KM and 6-sigma are shared commonly, an influential categorized methodology will be set up, Brue, (2002). KM structure gives an absolute access to taking care of the issues in 6-sigma ventures Clifford, (2001). Each of them additionally plans to manage improvement and viability and impact another. S. Crom, (2008).

\section{LITERATURE REVIEW}

\section{Knowledge Management}

Knowledge management was considered a systematic approach which is applied for capturing, structuring, and disseminating knowledge all over an organization. As a result, the organization's performance would increase in terms of working faster through reuse and the use of best practices. This includes reducing the costs of reworking data from project to project (Nanoka \& Takeuchi,1995). Effective management of knowledge plays an important role in the improvement of organizational competitive advantage through sharing of best practices, achieving better decision making, faster response to key institutional issues, better process handling, and improved people skills; and is essential to long-term organizational effectiveness. According to Pitt, M., \& MacVaugh, J. (2008)), knowledge management as any process or practice of creating, acquiring, capturing, sharing and using knowledge, wherever it resides, to enhance learning and performance in organizations which means the knowledge must be generated, after generating the knowledge it must be acquired, after that knowledge needed to be captured or stored so that everybody can use the knowledge when it is needed.

According to Cricelli, L., \& Grimaldi, M. (2008). , KM best practices include:

- Creating precise systems that permit assuming as how to stream to the right people at the ideal time;

- Focusing on significant business issues to maintain a strategic distance from redundant attempts, expand promptness the moment to capability, make remarkable Knowledge Management (KM) to the business, and cross constraints and capacities;

- $\quad$ Applying vibrant techniques;

- Enabling new knowledge to be created and new issues to be clarified; and

- Placing the Management fixation on effective communication, inclusion, requirement, and knowledge related behavior.

Two various types of knowledge should be perceived from each another. External knowledge that can be fundamentally shared and is consistently all around apparent; its reassign is potential through created course (Korth, 2007). Tacit Knowledge (TK) then again is a great deal more unpredictable to expressive; it is exceptionally individual, setting specific and exchanged predominantly in the progression of shared communications (Nonaka, 1991). Running with model describes the constituent of data and applies to knowledge association where TK is supported and changed over into Explicit Knowledge (EK) and then into TK (Nonaka, 1995, p.62). Pathirage, et. al., (2008) validated that knowledge has ended up being important organizational resource. Knowledge includes TK as well as EK. If there should arise an occurrence of EK, it expresses about perceived knowledge and implicit passes on personal learning, Harris, (2008), Plessis, (2007). EK is documentable and sharable through IT while TK abides in workers' brain. In this knowledge world, massive number of firms is getting the chance to be learning driven keeping in mind the end goal to perform and succeed the high passionate edge. Sireteanu and Grigoruta (2007) recommended that Universities can appreciate their rule objective as a learning association and present educational programs that chains models and courses of action subjected through KM, proposing to gain information to utilize influential performance, with an accent on updating capability, appropriateness and advancement. Ababneh (2008) had concentrated on the impact of KM and organizational learning in relationship with improvements. The extent of KM implies the philosophies, practices, scattering, processes, and policies, orderly, formal and casual procedures (Deng and Poole (2008).

\section{Six Sigma}

6-sigma is an engineered and thinking framework for upgrading business, product / service and process improvement that are subject to quantifiable techniques and rational procedures for fulfilling clients' objectives and minimizing defect rate. Three standard clarifications behind 6-sigma use are Customer's fulfillment, reducing action time and number of deformities. Numerous organizations have taken after the flourishing case of firms like Motorola and General Electric (GE) and actualized. 6-sigma. Six Sigma is creative talent „to support efficiency, help boosting market and create consumer loyalty by furnishing organizations with a planning of mediations and factual devices that can prompt the development onward advantage and enhancing Quality" (Harry, 1998, p. 60). GE that completed 6-sigma under its CEO Jack Welsh and that rolled out this development move towards a great degree especially favored depicts it as "the most essential venture GE has ever endeavored" (Brue, 2002, p. 7). The firm reported only three years after its utilization more than \$2 billion of store resources (General Electric 1999 Annual Report, p. 5). The results of 6-sigma depends upon estimations and to keep up a 
course of action inside its cutoff focuses so generally no noncompliance happen. W. Edwards Deming, to a great degree all around vitalizing and regarded Quality power, described in a talk to Japanese organization in 1950 the utilization of quantifiable mechanism as a "marvelous new instrument" important in a collecting conceived cost speculation resources and Quality changes (Deming, 1950). The Greek letter Sigma is utilized as the candid picture for calculating the deviation. The Sigma levels gauge the DEFECTS PER MILLION OPPORTUNITIES (DPMO) and goes for keeping the strategy inside its upper and lower control limits, i.e. \pm 6-sigma around its mean. Thusly, just 3.4 DEFECTS are being experienced per one million OPPORTUNITIES enduring that the techniques average floats unmistakably by as much as 1.5 standard deviations. Motorola developed this origination in eighties. The Quality Assurance gather fundamentally centered around the satisfaction with the Client's expectations and investigated the refined items/services for defects. Motorola needed to focus on its adequacy with a specific end goal to not to create defective product while in the meantime enhancing consumer satisfaction (Kumar and Gupta, 1993). Organizations, for instance, General Electric, Allied Signal, Honeywell and various others took after not long after besides made it a fundamental part into their organizational improvement works out (General Electric 1997 Annual Report, p.6) making "6-sigma the marvelous get ready for new 21st century GE activity" (General Electric 2000 Annual Report, p. 6). The five phase approach of 6-sigma is known as DEFINE, MEASURE, ANALYZE, IMPROVE, and CONTROL (DMAIC). In the first stage, project and scope and moreover the money related impact are seen (Define). This is straggled by social occasion data for measuring the present procedures implementation (Measure), considerable hidden drivers of defects (Analyze), advancement the technique (Improve) and in conclusion developing measures to keep up the developments made (Control). Clifford (2001) certifies that this commitment is basic as or else 6sigma would basically be another corporate winning prevailing fashion, the most state-of-the-art mode in an enlarged parade of must-have suitability seethes that constantly widened totally through corporate America". The technique involves a pyramid of 6-sigma specialists, called Belts, and two basic processes: the (DMAIC) methodology and (DFSS) Design for 6-sigma process. Contained by processes, some 6-sigma best practices are obvious:

[1] Dynamic interest of top Leadership,

[2] Senior official going about as full-time Manager of the project,

[3] Spotlight on evaluation based upon data driven results,

[4] Accountability for money related outcomes,

[5] Recruitment of full-time and low safeguarding Belts, and

[6] Efficient organizing for prospect pioneers.

\section{Enhancing Knowledge Management with 6-sigma}

Pearson (2000) defines the end of the Information Revolution and the start of the Knowledge Revolution. This joins a prearranged approach, and also dealt with information investigation as a benchmark for basic leadership. Sveiby, K. E. (2001). . The destinations of 6-sigma however are as per the outline of KM as a „process of improving activities through better information and obligation" Lyles, M. A., \& Schwenk, C. R. (1992). General Electric (GE), related its prosperity with this framework by setting up a society that "was keen on change, hungry to learn and eager to move quickly on a better than average idea."(General Electric 1998 Annual Report, p. 3). Various associations, for instance, Honeywell and Raytheon, both having a long history in applying the 6-sigma framework, consider this to be a fair way to deal with offer best practices and interpret it as „a key segment of the learning strategy" (Raytheon 2006 Annual Report, p. 3 or Honeywell 2006 Annual Report). Knowledge and experience from these "process authorities" is required remembering the final objective to handle the endeavor of lessening deformations inside an association. Socialization practices for group building happen persistently in the fundamental portion of the DMAIC methodology. This improves the understanding of the target moreover helps removing potential correspondence impediments. The Externalization changes over contingent information of the person into EK; to a great degree expected device is the Ishikawa diagram. Pictures and layouts are delivered normally all through the swapping of TK subsequently making a far reaching considerate of the entire change and likely interpretations for its defects. By analyzing influences among routine of essentials and considering and understanding circumstances and end results, EK ends up being new EK (Combination). Finally, Internalization happens as people happen to obvious with the new procedure therefore early implied learning. This hierarchical learning game plan system is constant and ideally makes a "Knowledge Spiral" as it crosses departmental points of confinement. TK gets the opportunity to be authoritative information as it moves from a man to a gathering to the association (Nonaka, 1995). Both 6-sigma and KM share a noticeable component in a business world to the top with change activities and upgrade rationalities. Totally through6sigma, KM addresses three issues:

i) The engaged environment,

ii) Using learning in the organizational environment, and

iii) Decreasing duplication of endeavors.

To display the KM philosophy in a basic approach, Raytheon (2012) current a four phase procedure: CREATE, CAPTURE, SHARE, and REUSE. Bread cook said, "You can see that we've merged benchmarking as a noteworthy part of that take into authority, approach and groups of practice also. In all probability, we have to reprocess knowledge, with the objective that we have lower nuisance and we get set up arrangements all the more rapidly and rapidly."Among distinctive focuses 
arranged groups, Raytheon supports Communities of Practices (CoPs) for both 6-sigma and KM. KM champions propel the four phase KM process in every business and firm. "Our philosophy was to choose KM champions that were in the 6-sigma master populace," said Baker (2014). "So we required the change managers, perhaps, that were by then arranged to be the KM champions." Efforts are under methodology to discover extra groups, give synergistic apparatuses and resources to CoPs, and build interest. Experts in both fields can get from each other. 6-sigma can get from KM how to perceive learning and procedures. Joseph Hofer-Alfeis from Siemens said, "6-sigma is sorted out to the way of items and procedures. In the event that you consider a learning candid to goodness business, 6-sigma for data quality' - the nature of the capacity, the nature of information streams, and the nature of description information - ought in like way be a to an extraordinary degree charming thing. Furthermore, what we do with our business visionaries, when you make an animating procedure, is a 6-sigma framework; and it winds up in business change practices by enhancing the Knowledge." Preston (2006), Kingsley Martin (2003) and WLE (2006) et.al described the following benefits which the organizations accomplished after implementing the best practices including KM practices and 6-sigma .

- $\quad$ Productivity and efficiency

- Knowledge sharing,

- Skill advancement and guidance

- Competitive advantage

- Marketplace visibility as a high-tech firm

- Capability to express effort to experienced experts

- Consistency of work product across offices or practice areas

- Quicker release times

- Quality control

- Reduced aggravation penetrating for documents

- Customer partnership

- Helps make certain the precise in sequence gets to the right people at the right time to make the right decisions

- Enhanced team announcement

- $\quad$ Reduced problem solving time

- Enhanced profitability consistency

- Improved project Management customer participation reduced design cycle time close to market business process improvement

\section{USING KM TOOLS IN DIFFERENT PHASES OF DMAIC}

\subsection{Define Phase}

One of the extensive motivations behind DEFINE stage is a complete clarification of issue. Essentially, a pool brimming with issues is craved to take in every one of them and to recognize indispensable and imperative ones, yet for the reason that of absence of these resources, the problem is not prominent suitably Pearson (2000). In addition, KM inference taking into description Knowledge maps is another issue. The reason for this mechanism is acceptance of knowledge inadequacies and insufficiency in the organization Sveiby, K. E. (2001). The learning of Pareto Chart, Kano Analysis, SIPOC Process Map Functional and Deployment Map and so forth for better depiction of the procedure is particularly fundamental to the extent Definition stage is concerned Lyles, M. A., \& Schwenk, C. R. (1992). Other pleasing presence of KM in this stage is statement and determination of appropriate principal in various fields to differentiate the issue / problem. A champion amongst the most fundamental inspirations driving this Defining stage is customer affirmation and Voice of Customer (VOC). 6-sigma has an extensive look to customer area. In spite of the technique that VOC are well thought-out as one of described source of issues in 6-sigma, envisages disclose a team number of 6-sigma ambles guide to consumer reliability enhancement and in decay most activities wanted to reduction of categorized cost assertiveness and potential advancement within integrated sources. Increasingly attractive properties of assumption leaning in 6-sigma philosophy are self-possessed as per business activities. (Raytheon 2006 Annual Report, p. 3 or Honeywell 2006 Annual Report). Key desire the methodology which helps Voice of Customers (VOCs) in KM likewise is Customer KM. To be sure, current affirmation happened as a result of customer fundamentals are not available with reliable situation or doesn't embrace every degree. "Client Knowledge" is a self-motivated strategy of practice, worth and sensible origination [Henning Gebert, 2003]. It implies Client understand the compulsory knowledge for basic leadership for shopping and the firm likewise secure client's understanding knowledge and his existing requirement which can take benefit amid development of new products. Thus, KM framework in an association ends up analyzing VOC in better from and to clear up Client's genuine need lastly to make appropriate Critical to quality (CTQ). Define Activities include the followings as per M. C. Becker, (2001).

- $\quad$ Classify the Assignment,

- $\quad$ Nominating Champion and Project Sponsor

- Define Client's Requirements and Critical to Quality (CTQs) 


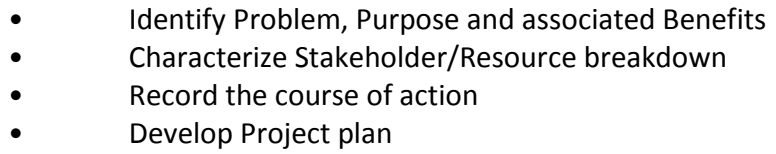

Define Quality Tools include the followings as per G. Brue, 2002

- Project Contract and Plan

- Effort/ Impact Analysis

- $\quad$ Process Mapping Tree Diagram

\subsection{Measure Phase}

A portion of the straightforward decisions of this stage comprise of recognizing premier issues obviously, far-sighted examples by constructing the application of Knowledge and to make clear the dimensions and accessible 6-sigma development. The most fundamental accomplishments of Knowledge frameworks and KM systems are to build up an appropriate infrastructure for CODIFICATION, STORAGE, DATA RETENTION, and in wrapping up ideal extraction and deployment. (D. Gilmour, (2003). CODIFICATION, ORGANIZATION AND ACQUIRING CONSEQUENCES of this stage for future use consultancy relationship of 6-sigma ambles: One of the most indispensable issues that specialists standardize them was to check emphasized practices in future and to support potential assessment. The information of the followings is key to be inclined to an appropriate approach to have improved Knowledge about the MEASUREMENT stage Harry, M.J. (1998).

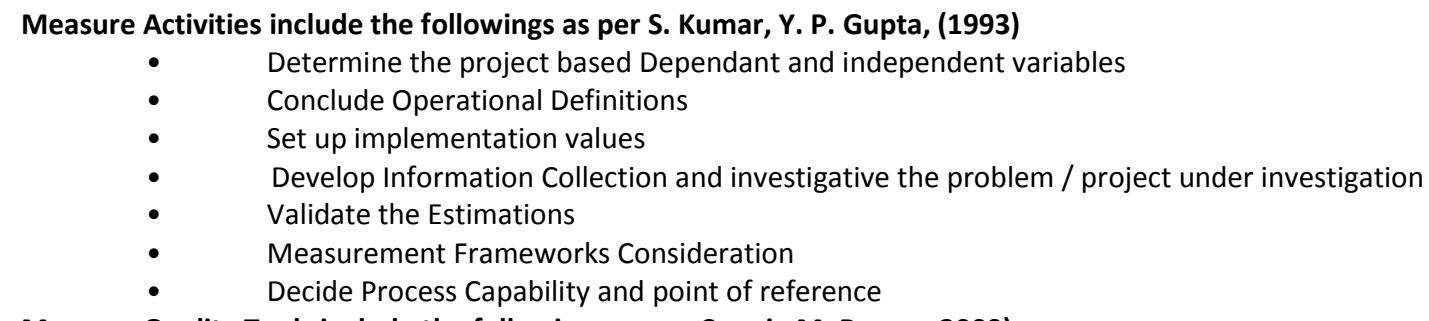

Measure Quality Tools include the followings as per Connie M. Borror, 2009)

- $\quad$ Quality Function Deployment (QFD)

- Measurement Systems Analysis (MSA)

- Process Capability

\subsection{Analyze Phase}

KM framework covers this topic precisely. The knowledge and better understanding of Main cause Analysis, 5 Whys, Statistical Data Plots, Hypothesis Testing, СTQ Flow-down is particularly indispensable to the extent Analysis stage is apprehensive (Nonthaleerak, P., \& Hendry, L. (2008). Choosing the finest extract to join in meetings to create new ideas is a standout amongst the mainly crucial services of KM practices to 6-sigma . Bennet, A., \& Bennet, D. (2004). The knowledge of the followings is indispensable to be addressed in a suitable manner to have enhanced understanding about the ANALYSIS PHASE (Kayworth \& Leidner, 2003)

\section{Analyze Activities}

- Make point of reference the course of action and or Products /Projects / Services

- Institute contributory associations Utilizing relevant Knowledge of the processes involved

- Investigation of the procedural plan

- $\quad$ Establish Root Cause(s) utilizing the related Information

Analyze Quality Tools

- Statistical examination of information

- $\quad$ Cause and effect diagram

- Pareto diagram, Run chart, Scatter graph etc.

\subsection{Improve Phase}

The essentially worth mentioning goal of this stage integrates knowledge of critical rational combination, coordination, clarification, perceiving risks and executing arrangement of configuration, modernization, conceptualizing and consultancy are the most central fundamentals of this stage (Womack \& Jones, 1991). Fundamental leadership needs osmosis amid an infinite region of knowledge which are spread throughout the organization. It infers associated person for fundamental organization must take a glance at essential data among organization and endeavor to trade it to other collaboration in a 
persuaded time. A champion amongst the most key inspirations driving KM is seeking inadequacy, conveying new knowledge and moving towards imagination. Chen, D. C., \& Holsapple, C. W. (2009). For perceiving reactions for improvement, specialists' thoughts are generally basic. Henceforth, specialty part and their suitable decision and reality of scrutinized past encounters and knowledge are obviously guaranteed. If these responses are not significant, the firm will keep running over considerable measure of losses. The information of the followings is basic to be tended to in a reasonable way to have enhanced comprehension about the IMPROVE STAGE (Holsapple, C., \& Joshi, K.D. (2005).

\section{Improve Activities}

- $\quad$ Build up interpretation alternatives

- Appraise Risks and advantages of determination of substitutes

- Authorize resolution by means of a lab trial

- Realize resolution

- $\quad$ Establish revelation efficiency using Data

\section{Improvement Quality Tools}

- Design of Experiments (DOE)

- $\quad$ Failure Mode and Effect Analysis (FMEA) Risk assessment

\subsection{Control Phase}

Documentation, change exploration, expansion of Improve stage results in a sustainable structure, are the most essential ones in this stage. Moreover, group organizing, accumulation and in Conduction of lessons, prospective understandings and proposal of future maneuvers are the systems of this stage which have a strong relationship with KM (Brown, J. S., \& Duguid, P. (2000). Change protection joins utilizing filed experiences, making utilization of the Tacit and explicit Knowledge. The data and better appreciation of Control Charts, Out of-control Action Plan, Capability Flow-up is essential to the degree Control stage is concerned. O'Dell, C. \& Grayson, C.J. (2004)

Using KM gives acceptance of making of learning acquired in IMPROVE and control stage and as it were responsibility and CLASSIFICATION, CODIFICATION, STORING AND SHARING them. By running learning in KM cycle, they constantly get the opportunity to be all-embracing and redesign that their course of action and time get the chance to be possible quickly. Wolford, Dan, \& Kwiecien, S. (2004).

Moving as per KM and changing to learner association, complete preparing, information taking care of and systematic obtained information in the best way. Honestly, this goal is realized totally and especially by KM. Holsapple, C., \& Joshi, K.D. (2005).

\section{Control Activities}

- Conclude desired Controlling parameters

- $\quad$ Realize and validate Controls

- Build up Reassign planning

- Comprehend advantages of Implementing resolution

- Close up the assignment and

- Correspond outcomes

Control Quality Tools

- Statistical Process Control (SPC)

- Out of Control Action Plan

- Plan modifications to eliminate the deficiency

\section{METHODOLOGY}

Both KM and 6-sigma are quickly cautious business association frameworks with essential thinking and process improvement strategies. Specialists in both fields can get benefit from each other. by having detailed qualitative analysis of the researches carried out by the eminent persons in this field. Data are gathered from written descriptions of past research articles etc. This study was conducted to develop a conceptual framework based upon the factors about the perceived benefits which Knowledge based and 6-sigma oriented organization can achieve after implementation of these best practices.

Figure 1: Conceptual Framework for Organization after Implementation of KM and 6-sigma Best Practices 


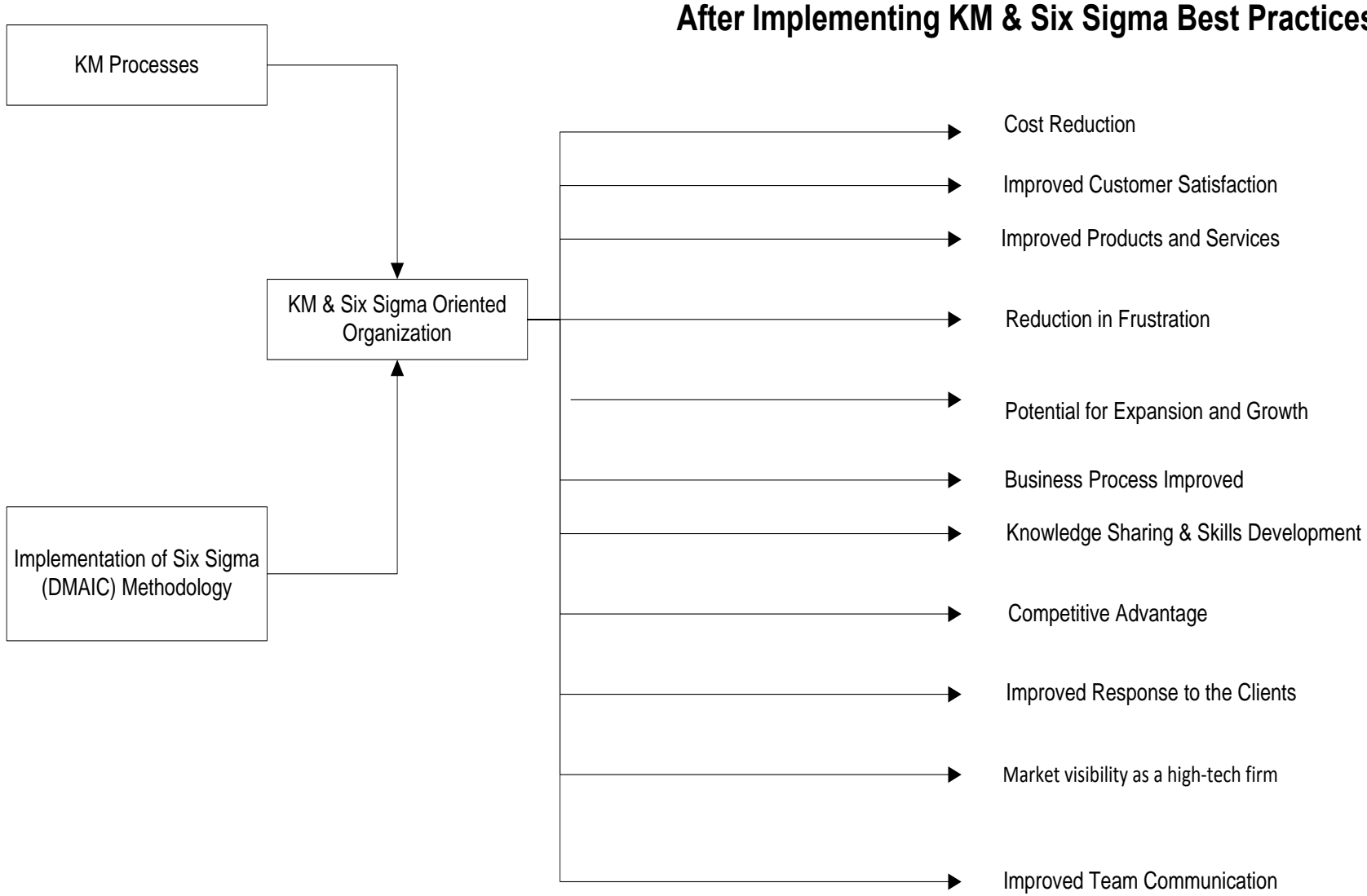

\section{CONCLUSION}

In learning focused financial structure arena, it is difficult to accomplish strong change for the advantage of relationships and associations. Starting now, knowledge is considered as the most crucial resource, along these lines, in conclusion with no exact perspective and appropriate device every firm will be unproductive consistently, KM that had a short life erase this test impressively and sensibly. 6-sigma ,one of the productive and manageable system that its accomplishments have made up-to-date change. These two outstanding judgments have typical focuses in their motivation and approach and are relating to each other and swing into a powerful management approach in an organization. As demonstrated by said thinkers about, using productive gadgets of KM have predominantly dealt with effect on use and support of 6-sigma tries and its health help. Representatives being displayed to 6-sigma rambles through their commitment as partners share their comprehension and furthermore development of new Knowledge. Both are important resources as they help assembling a learning organization being a source of high significance. The associations need to stimulate the use of such best practices including Knowledge Management and Six Sigma. This won't just build up the continuous accomplishments to turn up a learning relationship also have the benefit of perhaps reducing the push time of actions in the course of dominant work on dissemination and function. The author proposes the following conceptual framework about the perceived benefits which Knowledge based and Six Sigma oriented organizations can achieve after implementation of these best practices.

\section{REFERENCES}


Brue, G. (2015). Six Sigma for Managers, (Briefcase Books Series). McGraw Hill Professional.

Karthi, S., Devadasan, S. R., Murugesh, R., Sreenivasa, C. G., \& Sivaram, N. M. (2012). Global views on integrating Six Sigma and ISO 9001 certification. Total Quality Management \& Business Excellence, 23(3-4), 237-262.

Helms, R., Ignacio, R., Brinkkemper, S., \& Zonneveld, A. (2010). Limitations of network analysis for studying efficiency and effectiveness of knowledge sharing. Electronic Journal of Knowledge Management, 8(1), 53-68.

Anand, G., Ward, P. T., \& Tatikonda, M. V. (2010). Role of explicit and tacit knowledge in Six Sigma projects: An empirical examination of differential project success. Journal of Operations Management, 28(4), 303-315.

Weldy, T. G. (2009). Learning organization and transfer: strategies for improving performance. The Learning Organization, 16(1), 58-68.

The Certified Quality Engineer Handbook, Third Edition, ed. Connie M. Borror, ASQ Quality Press, 2009, pp. 321-332.

Chen, D. C., \& Holsapple, C. W. (2009). Knowledge Shared is Power: Utilizing Knowledge Management Activities to Replicate Lean Sigma Best Practices. Knowledge Management \& E-Learning: An International Journal (KM\&EL), 1(2), 90-102.

Nonthaleerak, P., \& Hendry, L. (2008). Exploring the six sigma phenomenon using multiple case study evidence. International Journal of Operations \& Production Management, 28(3), 279-303.

Pathirage, C., Haigh, R., Amaratunga, D., \& Baldry, D. (2008). Knowledge management practices in facilities organisations: a case study. Journal of Facilities Management, 6(1), 5-22.

Lopez-Nicolas, C., \& Molina-Castillo, F. J. (2008). Customer Knowledge Management and E-commerce: The role of customer perceived risk.International Journal of Information Management, 28(2), 102-113.

Arendt, M. (2008). Six sigma and knowledge management. Economics and Organization of Future Enterprise, 2(2), 14-20.

Gowen lii, C. R., Stock, G. N., \& McFadden, K. L. (2008). Simultaneous implementation of Six Sigma and knowledge management in hospitals. International Journal of Production Research, 46(23), 6781-6795.

Cricelli, L., \& Grimaldi, M. (2008). A dynamic view of knowledge and information: a stock and flow based methodology. International Journal of Management and Decision Making, 9(6), 686-698.

Ababneh, R. I. (2008). The impact of knowledge management and organization learning on organizational innovation: The case of the greater Amman Municipality in Jordan.

Pitt, M., \& MacVaugh, J. (2008). Knowledge management for new product development. Journal of Knowledge Management, 12(4), 101116.

Sireteanu, N. A., \& Bedrule-Grigoruta, M. V. (2007). Perspectives of knowledge management in universities. Available at SSRN 1029990. Choo, A. S., Linderman, K. W., \& Schroeder, R. G. (2007). Method and context perspectives on learning and knowledge creation in quality management. Journal of Operations Management, 25(4), 918-931.

Dahlgaard, J. J., \& Mi Dahlgaard-Park, S. (2006). Lean production, six sigma quality, TQM and company culture. The TQM magazine, 18(3), 263-281.

Kevin D. Barber and J. E. Munive-Hernandez, Process based KM system for continuous improvement, Journal of Quality \& Reliability Management, pp. 1002-1018, 2006

Lee, K. C., \& Choi, B. (2006). Six Sigma management activities and their influence on corporate competitiveness. Total Quality Management \& Business Excellence, 17(7), 893-911. (Raytheon 2006 Annual Report, p. 3 or Honeywell 2006 Annual Report)

Lin, C., Yeh, J. M., \& Tseng, S. M. (2005). Case study on knowledge-management gaps. Journal of knowledge management, 9(3), 36-50. Ricondo, I., \& Viles, E. (2005). Six Sigma and its link to TQM, BPR, lean and the learning organisation. International Journal of Six Sigma and Competitive Advantage, 1(3), 323-354.

MC Becker, N Lazaric (2005), RR Nelson, SG Winter Industrial and Corporate Change 14 (5), 775-791.

Holsapple, C., \& Joshi, K.D. (2005). A Formal Knowledge Management Ontology: Conduct, Activities, Resources, and Influences. Journal of the American Society for Information Science and Technology, 55(7), 593-612.

6 Jamieson, R., \& Handzic, M. (2004). Framework for Security, Control and Assurance of Knowledge Management Systems. Handbook on Knowledge Management 1, Springer-Verlag, Belin Heidelberg, 477-505. 
O'Dell, C. \& Grayson, C.J. (2004) Identifying and Transferring Internal Best Practices. Handbook on Knowledge Management 1, SpringerVerlag, Belin Heidelberg, 601-622.

Wolford, Dan, \& Kwiecien, S. (2004). Driving Knowledge Management at Ford Motor Company. Handbook on Knowledge Management 2, Springer-Verlag, Belin Heidelberg, 501-510

Antony, J. (2004). Six Sigma in the UK service organisations: results from a pilot survey. Managerial Auditing Journal, 19(8), 1006-1013.

Bennet, A., \& Bennet, D. (2004). The Rise of the Knowledge Organization. Handbook on Knowledge Management 1, Springer-Verlag, Belin Heidelberg, 3-20.

Linderman, K., Schroeder, R. G., Zaheer, S., Liedtke, C., \& Choo, A. S. (2004). Integrating quality management practices with knowledge creation processes. Journal of Operations Management, 22(6), 589-607.

Linderman, K., Schroeder, R. G., Zaheer, S., \& Choo, A. S. (2003). Six Sigma: a goal-theoretic perspective. Journal of Operations management,21(2), 193-203.

Sung H. Park, Six Sigma for Quality and Productivity Promotion, Asian Productivity Organization, ISBN: 92-833-1722-X, Page 143_146, 2003

Gebert, H., Geib, M., Kolbe, L., \& Brenner, W. (2003). Knowledge-enabled customer relationship management: integrating customer relationship management and knowledge management concepts [1]. Journal of knowledge management, 7(5), 107-123.

Treichler, David, Carmichael, Ronald, Kusmanoff, Antone, Lewis, John \& Berthiez, Gwendolyn, (2002), “Design for Six Sigma: 15 Lessons Learned", Quality Progress, January, pp. 33-42.

Joyce, B. R., \& Showers, B. (2002). Student achievement through staff development. Ascd.

Biolos, J. (2002). Six sigma meets the service economy - six sigma: it's not just for manufacturing. Harv Manag Updat, 7, 3-5.

G. Brue, 2002. Six Sigma for Managers, McGraw-Hill, New York, NY D. Gilmour, (2003)

Black, A. R., Black, J. D., \& Azizkhan-Clifford, J. (2001). Sp1 and krüppel-like factor family of transcription factors in cell growth regulation and cancer.Journal of cellular physiology, 188(2), 143-160.

Clifford, L. (2001). Why you can safely ignore Six Sigma. Fortune, 143(2), 140.

Brown, J. S., \& Duguid, P. (2000). The social life of information. Harvard Business Press.

Sveiby, K. E. (2001). A knowledge-based theory of the firm to guide in strategy formulation. Journal of intellectual capital, 2(4), 344-358.

T. A. Pearson, (2000). Six Sigma and the Knowledge Revolution. Annual Quality Congress, 54(0), p. 723-727

Lyles, M. A., \& Schwenk, C. R. (1992). Top management, strategy and organizational knowledge structures. Journal of management studies, 29(2), 155-174.

Harry, M.J. (1998). Six Sigma: A Breakthrough Strategy for Profitability. Quality Progress, 31(5), p. 60-64.

Nonaka, I., \& Takeuchi, H. (1995). The knowledge creation company: how Japanese companies create the dynamics of innovation. Oxford University Press. New York, USA, 304.

Nonaka, I. (1991). Models of knowledge management in the West and Japan. 